\title{
Ağız Diş Sağlığının Yaşam Kalitesine Etkisi ve Yaygın Değerlendirme Yöntemleri
}

\section{Impact of Oral Health on Quality of Life on and Current Examination Methods of Those Effects}

\section{ÖZ}

1946’da Dünya Sağlık Örgütü, sağlığı ‘sadece hastalık ve sakatlığın yokluğu değil tam olarak fiziksel, zihinsel ve sosyal refahın varlığı' olarak tanımladı ve bundan otuz yıl sonra hastalıkların tanı ve karakterizasyonunda hastaların hastalığa yönelik algılarının ne denli önemli olduğu vurgulanmaya başlandı. Bu şekilde tıbbi, katı bir biyolojik modelden, işlevselliği, psikolojik ve sosyal refahı da içeren sosyo-çevresel bir modele geçiş genel sağlık ve ağız diş sağlığı alanlarında uygulanmaya başlandı. Amerikan Diş Hekimleri Birliği ağız sağlığının işlevsel, yapısal, estetik, fizyolojik ve psikososyal bir sağlık durumu olduğunu ve bireyin genel sağlığı ve yaşam kalitesi için önemli olduğunu bir karar olarak yayınlamıştır. Bu bilgiler ışı̆̆ında ağız diş sağlığını bozan durumların hasta odaklı veriler ile bireylerin yaşam kalitelerine etkilerinin güncel olarak değerlendirilmesi ve bilgilerin derlenmesi amaçlanmıştır.

Anahtar sözcükler: Yaşam kalitesi, A ̆̆ız sağlığı.

\section{ABSTRACT}

In 1946, The World Health Organization defined health as the existence of physical, mental and social well-being, not just the absence of illness and disability' and thirty years after that, it was emphasized how important the patients' perceptions about the disease are in the diagnosis and characterization of diseases. In this way a socio-enviromental model including functional, psychological and social well-being transition from a medical, rigid biological model has begun to be implemented in general health and oral dental health areas. The American Dental Association published a decision that oral health is a functional, structural, aesthetic, physiological and psychosocial health condition and is important for the general health and quality of life of the individual. In the light of the current information we aimed to review the status of patient-centered dental health problems and their effects on the quality of life of individuals.

Key words: Quality of life, Oral health.

Yaşam kalitesi kavramının ekonomiden sağllğa, politikadan sosyal bilimlere kadar pek çok farklı disiplin tarafından ele alınması nedeniyle bu kavram için genel bir tanım yapılması zorlaşmaktadır $(1,2)$. 1946'de Dünya Sağlık Örgütü (DSÖ), sağlı̆̆ı sadece hastalık ve sakatlığın yokluğu değil aynı zamanda fiziksel, zihinsel ve sosyal refahın varlığı olarak tanımladığında 'yaşam kalitesi' kavramı sağlık uygulamaları ve araştırmaları için önem kazanmıştır (3). Aslında yeni bir kavram değildir ve konuyla ilgili öncü

\author{
Ekin BEŞİROĞLU ${ }^{1}$ \\ Müge LÜTFIOĞLU \\ 1 Okan Üniversitesi Diş Hastanesi, \\ İstanbul, Türkiye \\ 2 Ondokuz Mayıs Üniversitesi \\ Diş Hekimliği Fakültesi, Periodontoloji \\ Anabilim Dalı, Samsun, Türkiye
}

Geliş tarihi / Received: 08.05.2018 Kabul tarihi / Accepted: 03.07.2018 DOI: $10.21306 /$ jids.2018.179

İletişim Adresi/Corresponding Adress: Müge LÜTFİĞLU

Ondokuz Mayıs Üniversitesi Diş Hekimliği Fakültesi, Periodontoloji Anabilim Dalı, Samsun, Türkiye

E-posta/e-mail: mugelutfioglu@hotmail.com 
çalışmaların Thorndike tarafından 1939'da başladığı ve her yıl 'yaşam kalitesi' başlı̆g 1 altında 1000'den fazla yeni makalenin yayınlandığı bildirilmiştir (4). Medikal literatürde sınırları belirlenmiş bir yaşam kalitesi değerlendirmesi ilk kez 1966 yılında Priestman ve Baum tarafindan meme kanserli hastalara yöneltilen 10 soruluk bir anket ile yapılmıştır $(5,6)$. "Yaşam kalitesi" terimi, Medline Bilgisayar Arama Sisteminde 1977 gibi yakın bir zamanda anahtar kelime haline gelmiştir ve bu tarihten sonra ilgi büyük ölçüde artmıştır. 1966 ve 1974 arasında, anahtar sözcük olarak 'yaşam kalitesi' listelendiğinde 40 makale bulunurken, bu 1986 ve 1994 yılları arasında 10.000 'in üzerine çıkmıştır $(7,8)$.

Takip eden zamanlarda, DSÖ de yaşam kalitesini 'bireylerin yaşadıkları kültür ve değerler sistemi içerisinde amaçları, beklentileri, ilgi alanları ve yaşam standartları doğrultusunda hayattaki pozisyonlarını algılama şekli' olarak tanımlamıştır $(9,10)$. Yaşam kalitesi kavramının temelde dört ana alanda değerlendirilmesi önerilmiş ve şu şekilde açıklanmıştır $(11,12)$ :

1. Kişisel içsel alan (değerler, inançlar, arzular, kişisel hedefler, sorunlarla başa çıkabilme becerisi vb.)

2. Kişisel sosyal alan (aile yapısı, gelir durumu, çalışma durumu, toplumun tanıdığı olanaklar vb.)

\section{Dışsal doğal çevre alanı (hava, su kalitesi vb.)}

4. Dışsal toplumsal çevre alanı (kültürel, sosyal ve dini kurumlar, toplumsal olanaklar, eğitim, sağl1k hizmetleri, güvenlik, ulaşım vb.)(11,12)

$\mathrm{Bu}$ temel kavramların değerlendirilebilmesi için yaşam kalitesinin objektif ve sübjektif göstergeleri bulunduğu ve yaşam kalitesini değerlendirirken objektif ve sübjektif göstergelerin beraber kullanılması gerektiği bildirilmiştir $(10,13,14)$. Yaşam kalitesinin objektif göstergesi olan 'Fiziksel İyilik Hali' bireyin günlük aktivitelerini ve kişisel bakımını başkasına ihtiyaç duymadan yerine getirebilmesini ifade etmektedir. Kişinin yaşam kalitesini tanımlamada objektif boyut önemli olmasına rağmen kişinin sübjektif algıları ve beklentileri bu objektif değerlendirmeyi gerçek yaşam kalitesi değerlendirmesine dönüştürür (2). Yaşam kalitesinin sübjektif göstergeleri ekonomik, sosyal ve psikolojik iyilik hallerini kapsamaktadır. 'Ekonomik İyilik Hali' içinde bireyin sağlık, barınma gibi temel ihtiyaçlarını karşılayabilmesi, iş güvencesine sahip olması, maddi açıdan geleceğe karşı kendini güvende hissetmesi gibi durumları barındırmaktadır. 'Sosyal İyilik Hali' bireyin sosyal ilişkilerinde ve toplumsal faaliyetlerinde yapması gerekenleri yerine getirebilmesi anlamına gelmektedir.
'Psikolojik İyilik Hali' içerisinde kişinin genel mutluluk ve doyum duygularının yer aldığı görülmektedir. Bireyin hayattan tatmin olması, değişik yaşam koşullarına ayak uydurabilmesi ve duygusal açıdan iyi olması anlamına gelmektedir $(10,14)$.

Sağlıkla İlişkili Yaşam Kalitesi: Sağlıkla ilişkili yaşam kalitesi genel yaşam kalitesinin alt bileşenidir. Bireyin hastalığını ve/veya hastalığa yönelik tedavi sonuçlarını nasıl algıladığına ve bireyin endișelerine odaklanmaktadır (15). Sağlıklı olma durumu ile ilgili beklentiler; oluşan aksaklık ve sakatlıkla başa çıkabilme becerisi kişinin sağlık algısını ve yaşamdan memnuniyetini büyük ölçüde etkileyebilir ve dolayısıyla aynı sağlık statüsüne sahip iki kişi çok farklı yaşam kalitesine sahip olabilir. Allison ve ark. (16) sağlıkla ilişkili yaşam kalitesinin 'dinamik bir yapı' olduğunu ve zamanla değişime uğrayacağını vurgulamışlardır. Çünkü bireysel tutumlar sabit değildir; zaman, tecrübe, baş etme, beklenti ve uyum gösterme gibi olgular tarafından değişebilmektedir $(14,16)$.

Günümüzde tüm bunlara ek olarak, bireyin hayatının doktorlar tarafindan erişilemeyen birçok yönünün de var olduğu ve sağlıkla ilişkili yaşam kalitesinin değerlendirilmesinde hastanın kendisinin değerlendirilmeyi yapacak en iyi kişi olduğu varsayılmaktadır. Hastalıklarının getirdikleri olumsuzluklara alışan ve bu olumsuzlukları kendileri için normalleştiren kronik hastalığa sahip bireyler, yaşam kalitelerinin sağlıklı bireylere göre daha üstün olduğunu düşünebilirler (17). Bu durum, yaşam kalitesinin dinamik bir yapıya sahip olması sebebiyle zaman içinde değişiklik gösterebileceği ve bireysel beklenti ve yaşam koşullarından etkilendiği şeklinde açıklanmaktadır (16).

DSÖ'nün sağlık tanımına da uygun olarak sağlıkla ilişkili yaşam kalitesini değerlendirme alanlarını Spilker 1996 'da (18) i)Fiziksel durum ii)Psikolojik durum iii) Sosyal etkileşim iv) Ekonomik ve/veya mesleki konum v) Dini ve/veya manevi durum olarak belirtmiştir. Hastalar tarafindan sağlıklarının nasıl algılandığı ve hastalığın olup olmadığının değerlendirilmesi; sağlıkla ilgili kaynakların yönlendirilmesi, sağlığın iyileștirilmesi, hastalık önleyici programların geliştirilmesi açısından önemli olduğu ve sağlığı hasta odaklı değerlendirmenin sağlığın da ölçümünde gerekli olduğu vurgulanmıştır $(8,18)$.

Ağız Diş Sağlığıyla İlişkili Yaşam Kalitesi: Ağız diş sağlığıyla ilişkili yaşam kalitesi sağlıkla ilişkili yaşam kalitesinin alt bileşenidir (19). Orofasiyal bölgedeki ağrı ve rahatsızlığın bireyin psikolojik, sosyal, fonksiyonel 
faktörler ve bireysel iyilik halini nasıl etkilediğini tanımlayan özelleşmiş bir durumun ifadesidir $(14,20,21,22,23)$. İlk defa II. Dünya Savaşı sırasında 'ağız sağlığıyla ilişkili yaşam kalitesi' kavramı, karşılıklı çenelerde altı dişin olmasının oral fonksiyonları yerine getirebilme göstergesi, iyi olma hali ve hizmete uygunluğu değerlendirmek için kullanılmıştır (24). Sağlıkla ilișkili yaşam kalitesinin değerlendirilmesinde kullanılan sağlık durumu ölçekleri tıbbın çeşitli alanlarında diş hekimliği alanlarına göre daha yaygın kullanılmaktadır. Ağız sağlık durumunun hasta odaklı ölçümüne duyulan gerekliliği ilk vurgulayanlar Cohen ve Jago olmuştur (25). Ağız sağlığını değerlendirirken yaşam tarzı, kültürel faktörler gibi sosyal indikatörlerin de değerlendirilmesi gerektiği, ancak bu şekilde sağlık politikaları geliştirilebileceği belirtilmiştir (25). Bunu takiben Reisine (26) 1984 yilında dental problemlere bağlı olarak oluşan iş gücü kaybının bir sosyal indikatör olduğunu ve ağız hastalıklarının sosyal etkisini araştırmaları ile vurgulamışlardır. Gift ve Atchison (27) ağı sağlığı, ağız sağlığ1 ile ilişkili yaşam kalitesi ve sistemik sağlık arasındaki etkileşimin anlaşılmasını geliştirmek amacıyla planladıkları çalışma ile ağı sağlığı alanındaki en önemli makalelerden birini yayınlamışlardır. Gift ve Atchison ağız sağlığını genel sağlığın ayrılmaz bir parçası olarak kavramsallaştırmayı ve ağı sağlığının genel sağlıkla ilişkili hayat kalitesine katkısını düşünmeye duyulan ihtiyacı vurgulamışlardır (27). Bu başlangıç çalışmaları ile sosyal faktörler incelenirken birey odaklı değerlendirme hakkında çok bilgi verilmemiştir. Sonuç olarak oral hastalıklar ve durumlar oldukça yaygındır ve çok sayıda bireyde yaşam kalitesini ciddi şekilde bozar; buna ek olarak işlev, görünüm ve kişiler arası ilişkiler de dahil olmak üzere yaşamın çeşitli yönlerini etkileyebilir (28). Hasta algısının hastalıkların teşhisi ve karakterizasyonunda birey tarafından hissedilen 'noksanlık algısını' da içermesi gerektiği 1977'de Engel tarafından önerilmiştir ve birey odaklı değerlendirmenin önemi vurgulanmıştır (3). Diş hekimliği alanında Locker sağlık sonuçlarını bireysel seviyededeğerlendirirken, bireyselölçeklerin kullanılması gerektiğini önermiş ve $1988^{\prime}$ de ağız sağlığının ölçümü ile ilgili kavramsal bir taslak olușturmuștur (29). Locker tarafından ağız ve diş sağlığını ölçmek için tanımlanan kavramsal sistem DSÖ'nün bozukluğun, sakatlı̆̆ın ve engelin sınıflandırılmasına dayanmaktadır ve 'ağız ve diş sağlığı sorunlarının' olası tüm fonksiyonel ve psikolojik sonuçlarını değerlendirebilmeye çalışmaktadır. Tanım gereği dişlerini kaybeden yani bir vücut bölümünü kaybetmiş insanlar 'sağlık bozukluğuna sahip' olmaktadır (29). Bu kavramsal çerçevenin yayınlanması, bu araştırma temasının diş hekimliğinde geliştirilmesinde önemli bir rol oynamıștır (30). Yakın zamana kadar, ağız ve diş sağlığı ile ilgili koşullarının değişiminin psikososyal sonuçları hayati tehlike oluşturma olasılı̆ğ bulundurmaması nedeniyle üzerinde çok da durulan bir konu olmamıştır. Ama güncel araştırmalar ile ağız ve dişlerle ilgili rahatsızlıkların diğer bozukluklar kadar ciddi duygusal ve psikososyal sonuçları olduğu vurgulanmaya başlanmıştır $(14,30,31,32)$.

Locker ağız sağlığı ölçüm modelindeki kavramların tanımları şu şekildedir;

1. Fonksiyonel Kisıtlılık: Çoğunlukla vücudun bileşenlerinin veya organlarının beklendiği gibi çalışmamasının bir sonucu olarak tanımlanmaktadır.

2. Rahatsızlık: Hastalığa verilen cevaptır. Hastaların ifade ettiği ağrı, rahatsızlık, fiziksel ya da psikolojik semptomlar örnek gösterilebilmektedir.

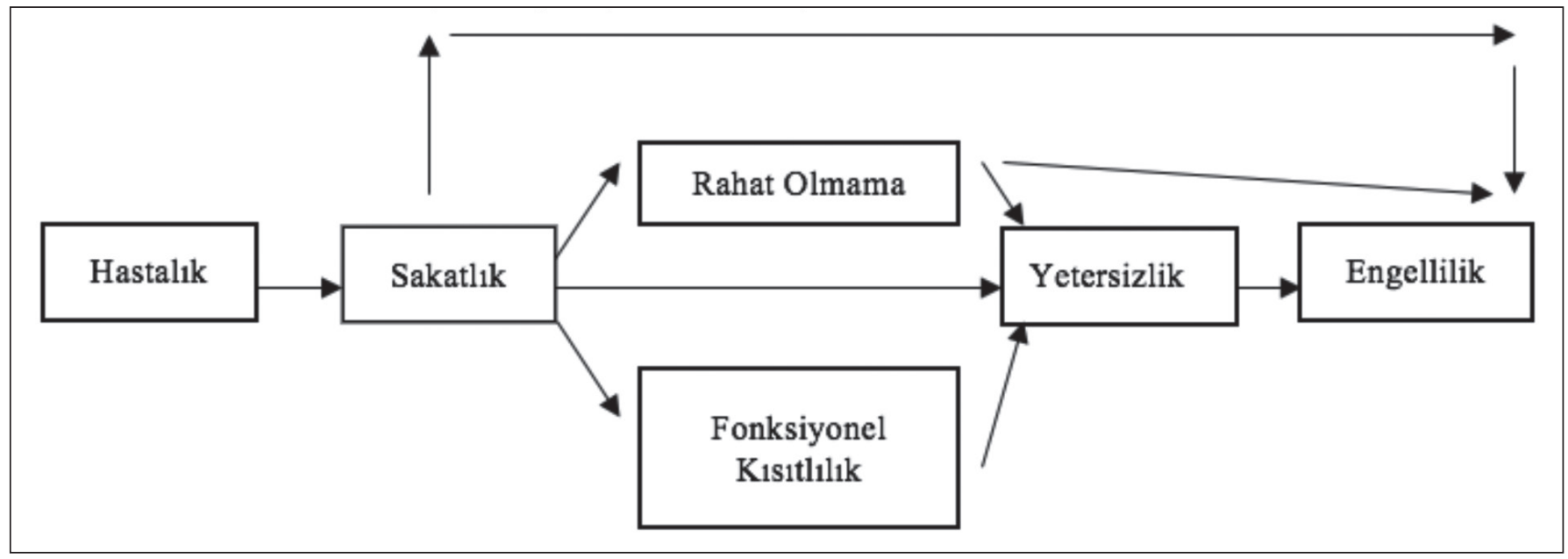

Şekil 1: Locker ağız sağlığı ölçüm modeli (29) 
3. Sakatlık: Doğum esnasında ya da sonradan olușan fiziksel, psikolojik ya da anatomik yapının yokluğu veya anormalliği olarak tanımlanmaktadır. Dişsizlik, periodontal hastalık veya malokluzyon örnek gösterilebilmektedir.

4. Yetersizlik: Normal kabul edilen yeteneklerin eksikliğidir.

5. Eksiklik: Bireylerin bulunduğu grup içerisinde sosyal beklentileri yerine getirememesidir.(29)

Ve yine Locker, genel sağlık ve ağız sağlığı arasında bir ayrım olmadığını, ağız boşluğunun vücut içinde yer aldığını ve bireyin 'otonomiye sahip' bir anatomik bölgesi olmadığını, ağız diş sağlığı ile ilgili hastalıkların bireyin iyilik hali ve yaşam kalitesini etkilediğini vurgulamıştır. (33). Günümüzde artık ağız sağlığ ile ilişkili yaşam kalitesi 'kişinin ağız sağlığıyla ilgili memnuniyetini, özgüvenini, yemek, uyku ve sosyal etkileşimlerde bulunurken kişinin rahatlığını' değerlendirmeyi hedeflemektedir ve ağız sağlığının devamlılığının genel sağlıklı olmanın gereklerinden biri olduğunu göstemektedir $(31,34)$.

Ağız sağlığı anlayışı kişinin 'ideal' ağız sağlığından ne anladığına, kültürel değerlere, genel sağlığına ve psikososyal mutluluğa göre değişmektedir. Diş çürügü ya da periodontal hastalık gibi oral hastalıklar yüksek prevalanslı hastalıklar olup sadece fiziksel değil aynı zamanda ekonomik, sosyal ve psikolojik etkilere de sahip oldukları bildirilmiştir (22). Periodontal hastalık toplumda farklı şiddette ve büyük oranda rastlanan, hastaların yaşam kalitelerini olumsuz yönde etkilediği bilinen bir ağız sağlığı sorunudur. Bu hastalıklar ölümcül olmamakla birlikte bireylerin beslenme, konuşma ve sosyalleşme gibi günlük aktivitelerini olumsuz etkiledikleri için genel iyilik hali ve yaşam kalitesi üzerine de olumsuz etkileri olduğu iddia edilmektedir $(32,35,36,37)$. Periodontal ataşman ve alveol kemiği kapsayan diş destek dokularında yıkıma yol açan periodontitis, ileri olgularda diş kaybına da sebep olabilmektedir. Ayrıca dişetlerinde kanama ve kötü ağız kokusunun yanı sıra dişeti çekilmesine, dişlerde sallanmalara, diş hassasiyetine ve bir takım davranışsal kısıtllılıklara neden olabilmektedir. Ağız sağlı̆̆ tat hissini etkileyebildiği, yemek yerken ağrıya neden olabildiği dolayısıyla rahat çiğnemeyi engellediği ve fiziksel başka bir takım engellemeler yaratabileceği için yaşam kalitesini etkileyebilmektedir (38).

Yapılan çalışmalarda ağız ve diş sağlığını etkileyen hastalıkların yılda ortalama 160 milyon saatlik iş gücü kaybına, okul çağındaki çocuklarda ise 51 milyon saatlik okul günü kaybına neden olduğu bildirilmiştir $(26,39)$.
Reisine (40) planladığı araştırmasında mevcut psikososyal etkileri anlatabilmek için sosyal indikatörlerin erişkinler için iş günü, çocuklar için okul günü kaybını değerlendirmiş ve kişi başına yıllık iş gücü kaybını 1,7 saat olarak belirlemiştir. Bu kayıp bireysel olarak tolere edilebilir ancak çok sayıda kişinin çalıştığ 1 kurumlarda bir bütün olarak düşünüldüğünde, yüksek miktarda iş gücü kaybı ve maliyete sebep olacağı belirtilmiştir (40). A ğız ve diş sağlığı sorunlarına duyulan bu ilgi sonucunda, son yillarda önemli bir araştırma konusu olmuştur.

Diş hekimlerinin geleneksel olarak yaptığı çalışmalarda çürük ve periodontal problem gibi hastalıkların tanımlanması ve toplumdaki sıklıklarının belirlenmesi gibi konular ele alınmaktadır. Bunların ölçümleri için çürük/kayıp/eksik diş $(\mathrm{DMF} / \mathrm{T})$ ve toplumdaki periodontal tedavi gereksinimi indeksi (CPITN) gibi indeksler kullanılmaktadır $(41,42)$. Bu ve benzeri indeksler hastalıkların varlığını, ilerleme durumları ve şiddetlerini değerlendirmektedir ama bireylerin sosyal içerikli konularla ilişkili değerlendirilmesi mümkün olamamaktadır $(14,20,43)$. Farklı çalışmalarda diş çürüğü ve periodontal ataşman kaybı gibi dental hastalıkların objektif olarak ölçülmesinin bireylerin hastalık algısını yansıtmaması nedeniyle, ağız sağlığıyla ilişkili yaşam kalitesinin değerlendirilmesinde fazla bir öneme sahip olmadıkları bildirilmiştir (44). Dental hastalıkların objektif ölçümleri (diş çürüğü varlığı, periodontal ataşman kaybı gibi) ve oral durumun hasta merkezli değerlendirme kriterleri arasındaki ilişkiyi değerlendiren araştırmalar çok yaygın olamamakla birlikte kanıta dayalı olarak belirlenmiş bu objektif ölçümler hasta merkezli değerlendirme kriterleri ile her zaman örtüşmeyebilmektedir. Bu durum sağlığın çok boyutlu yapısını ve sadece hekim değil hasta odaklı sonuçları da kapsayan bazı ölçekler geliştirme ihtiyacını ortaya koymuştur (14,45). Ağız sağlığıyla ilişkili yaşam kalitesinin değerlendirilmesinde kullanılan ölçeklerin duyarlılı̆̆g karmaşık ve tartışmalı bir konudur. Değerlendirilmeler arasındaki farkın ölçülebilir ya da subjektiviteden uzaklaşacak şekilde karşılaştırılabilmesi uzun dönem ve takip gerektiren çalışmalarda gereklidir. $\mathrm{Bu}$ nedenle değişimin ölçeklerde nicel hale getirilmesi önemli bir konudur. Locker değişimi ölçmenin 4 yolunu tanımlamıştır:

1. Önceki ve sonraki ölçümlerin karşılaştırılması

2. Takip skorundan başlangıç skorunu çıkararak skor değişimi hesaplanması

3. Evrensel değişim kararı

4. Evrensel değişim ölçekleri 
$\mathrm{Bu}$ yöntemlerin hepsi kullanılabileceği ancak hiç birinin evrensel olarak kabul edilemediği belirtilmiştir $(14,46)$. Başlangıç ve takip ölçümlerini karşılaştırmanın basit bir yöntem olabildiği ancak olumlu ve olumsuz değişikliklerin birbirini etkileyebileceği ve bu yüzden değişiklik etkisinin tam olarak belirlenmesinin güç olduğu bildirilmiştir $(14,46)$. Son bir yaklaşım; işlevsel bozuklukların ve bunların toplumsal sonuçlarının önem sırasına göre düzene koyulması olarak açıklanmıştır. Sonuçların önem sırası DSÖ'nün bozukluklar, engeller ve handikaplar kategorisine ve Locker'ın ağız sağlığının ölçülmesine ilişkin teorik çerçevesine dayanmaktadır. $\mathrm{Bu}$ yöntemi kullanarak sosyal etkilerin bir profili tanımlanabilmektedir. Ağı Sağlığı Etki Profili (Oral Health Impact Profile-OHIP), Günlük Yaşam Üzerine Dental Etki (Dental Impact on Daily Living-DIDL) ve Günlük Performansa Oral Etki (Oral Impact Daily Performance-OIDP) bu yolla oluşturulmuştur. Bu ölçeklerin her biri işlevsel ve psiko-sosyal iyilik halindeki sözlü sorunların sıklığını ve ciddiyetini ölçmeye çalışmaktadır (14).

\section{Ağız-Diş Sağlığını ve Yaşam Kalitesi İlişkisini Değerlendirmede Yaygın Olarak Kullanılan İndeksler:}

\section{Genel Ağız Sağlığı Değerlendirme İndeksi (General} (Geriatric) Oral Health Assessment Index) (GOHAI)

12 maddelik Geriatric Oral Health Assessment Index olarak ilk kez 1990 yılında Atchinson ve Dolan tarafindan ABD'de geliştirilmiştir ve daha sonrasında General Oral Health Assessment Index olarak yeniden adlandırılmıştır. 12 madde fiziksel fonksiyonların (yeme, konuşma ve yutma), psikososyal fonksiyonların (ağız sağlığıyla ilgili endişe, görünüşten duyulan memnuniyetsizlik, ağız sağlığ1 konusunda benlik bilinci ve oral problemler nedeniyle toplumsal ilişkiden kaçınma) ve ağrı ya da rahatsızlığın (ağrıyı hafifletmek için ilaç kullanımı) boyutlarını değerlendirmektedir. Katılımclar her 12 öğe için son üç ay içindeki deneyimlerini beşli Likert tipi ölçümlerle ( $0=$ hiç, $1=$ =nadiren, $2=$ bazen, $3=s 1 k$, $4=$ çok sık, $5=$ her zaman) cevaplandırmışlardır. 12 soru cevaplandirılarak 0-60 arasinda bir skor elde edilmektedir. GOHAI skorları '<50' düşük, '51-56' orta, '57-60' yüksek olarak derecelendirilmiştir. Oral durumu iyi olan ve hiçbir problemi olmayan kişilerin skorları yüksek olarak kaydedilmiştir $(47,48)$.

\section{Günlük Performansa Oral Etki (Oral Impact on Daily Performance) (OIDP)}

OIDP’nin temeli DSÖ'nün engellilik sinıflamasına dayanmaktadır. Kullanımı kolaydır. Yetişkin ve yaşlı popülasyonlarda kullanılan farklı düzenlemelerinin güvenilirlik ve geçerliliği başarıyla test edilmiştir. OIDP günlük aktiviteleri gerçekleştirme kabiliyeti üzerindeki oral etkileri değerlendirmektedir (49).

Ağız sağlığının günlük aktiviteler üzerindeki etkisini; yemek yeme, yediği yemekten zevk alma, uyuma ve rahatlama, gülümseme, gülme ve utanmadan dişlerini gösterebilme, konuşma, kelimeleri düzgün telaffuz edebilme, dişlerini temizleyebilme ve normal sosyal ilişki kurabilme gibi alanlarda değerlendirmektedir. Bireylere son 6 aydır ağız-diș sağlığı ile ilișkili problemler yüzünden bu aktiviteleri yaparken ne sıklıkla problem yaşadıkları sorularak değerlendirilmektedir (14,20). OIDP sıklığa göre belirlenen sekiz başlık üzerinden puanlanmaktadır: yemek, konuşma ve açıkça telaffuz, diş temizleme, uyku ve rahatlama, utanmadan gülümseme, duygusal durumu sürdürme, diğer insanlarla iletişim kurma ve sosyal ortamda başarı yürütmek. Kullanılan ölçekte aralıklar: (0) "hiç etkilenmedi", (1) "ayda bir kereden az", (2) "ayda bir veya iki kez", (3) "haftada bir veya iki kez" (4) "haftada 3-4 kez", (5) "her gün veya neredeyse her gün" $(50,51)$.

\section{Günlük Yaşam Üzerine Dental Etki (Dental Impact on Daily Living) (DIDL)}

AğıZ sağlık durumunun günlük yaşam kalitesi üzerindeki etkilerini belirlemeyi amaçlayan bu ölçek beş ana kategoride toplam 36 sorudan oluşmaktadır. $\mathrm{Bu}$ beş kategori konfor (diş kaybı, ağız kokusu, diş etlerinde kanama, hassasiyet), dış görünüş (dişlerin pozisyonu, rengi, görünümü), ağrı (spontan ağrı, çiğnemeyle ağrı, sıcak/soğukta ağr1, eklem ağrıs1), genel performans (ağr1 yüzünden stres, uykusuzluk, iş kapasitesinde düşüş, özgüvende sarsılma) ve yemek yemede kisitlllıktır (çiğnemede kısıtlılık, 1sırmada kısıtlılık). Her bir ifade şu şekilde kodlanmıştır: $(+1)=$ pozitif yanıt, $(0)=$ nötr yanıt ve $(-1)=$ negatif yanit $(14,44)$.

\section{Dental Etki Profili (Dental Impact Profile) (DIP)}

1993 yılında Strauss ve Hunt tarafından yayınlanmıştır. Hastaların olaylar karşısındaki algısını değerlendiren bir ölçektir. Yemek yeme, sağlık/iyilik hali, sosyal ilişkiler, romantizm olmak üzere dört alt başlık ve 25 sorudan oluşmaktadır. Sorular rahatlık, özgüven, tat alma, çiğneme ve isırma, gülme, sosyal hayat, konuşma, nefes, genel sağlık, günlük faaliyetlerine devamlılık, iş başarısı üzerine dişlerin veya protezlerin etkisini değerlendirmektedir (51). Sorular 'Size göre dişlerinizin veya protezlerinizin yemek yemeniz üzerine pozitif (iyi), negatif (kötü) etkisi vardır ya da hiçbir etkisi yoktur?' şeklinde olmaktadır. Tüm cevaplar arasında pozitif veya negatif cevapların yüzdesi toplanarak toplam skor hesaplanmaktadır $(52,53)$. 


\section{A ğız Sağlığıyla İlişkili Yaşam Kalitesi-Birleşik Krallık (Oral Health Related Quality of Life- United Kingdom) (OHRQoL-UK)}

İlk kez 2000 yllında McGrath ve Bedi tarafindan İngiltere'de oluşturulmuştur. Ağız sağllğının yaşam kalitesi üzerindeki etkilerini pozitif ve negatif alanda değerlendiren dört farklı kategoride 16 sorudan oluşmaktadır. Bu kategoriler sırasıyla; semptom (2 soru), fiziksel durum (5 soru), psikolojik durum (5 soru), sosyal durum (4 soru)'dur $(54,55,56)$. Ağı-diş bölgesiyle ilişkili hastalıkların yaşam kalitesi üzerindeki negatif etkilerinin, günlük yaşantıda sağlıklı durumun yarattığı pozitif etkilerin bireyler tarafindan fark edilmesine engel olduğu düşünülmüştür. Hem pozitif hem de negatif değerlendirme yapan OHRQoL-UK ölçeğinde elde edilen düşük skor ağız sağlığı ile ilişkili yaşam kalitesinin düşük olduğunu göstermektedir. OHRQoL-UK anketinde Likert ölçeğine göre skorlanan sorulara 1-5 arasında değer verilmektedir. Toplam 16 sorunun skoru toplandığında 16-80 arasında bir değer bulunmaktadır (54).

\section{Görsel Analog Skalası (Visual Analog Scale) (VAS)}

Sözcüklerin sübjektif deneyimin kesinliğini tanımlamada başarısız olabileceği ve dijital derecelendirmenin duygu olgusu üzerine yanlış kategorileri dayattı̆̆ı savunulmaktaydi. Bu nedenle VAS'ın sunduğu puanlama hassasiyetinin dijital ve sözel derecelendirme ölçekleriyle sağlanmasının imkansız olduğu ileri sürülmüştür. VAS özellikle değişimin ölçümü ve öneminin görülmesi için uygun bir ölçektir (57).

$\mathrm{Bu}$ ölçek $10 \mathrm{~cm}$ uzunluğunda bir hattır. $\mathrm{Bu}$ çizginin vertikal ya da horizontal yönde olması sonuçları etkilememektedir (58). Hasta sorulan soruya karşıllk olarak hissettiği durumu hat üzerinde işaretler ve işaretlenen kısım ve hattın başlangıç noktası arasındaki mesafe santimetre cinsinden ölçülür. $\mathrm{Bu}$ yöntemin avantajı klinikte kolay uygulanabilir olması, anlaşılır olması ve tüm hasta gruplarında uygulanabilir olmasıdır (57).

\section{Ağız Sağlığı Etki Profili (Oral Health Impact Profile) (OHIP)}

İlk olarak, DSÖ'nün Uluslararası Eksiklik, Yetersizlik ve Sakatlık Sinıflaması esas alınarak, 1994 yılında Avusturalya' da Sladeve Spencer tarafından uygulanmıştır $(59,60)$. Ağız bölgesiyle ilgili tüm medikal durumlarda kullanılabilen, ağız sağlığı ailesine ait bir yaşam kalitesi ölçeğidir. Ölçek Locker'ın kavramsal iskeletini esas almaktadır (61).
OHIP'deki 49 soru Locker' ın ağız sağllğının teorik modelini yedi kavramsal boyutta formüle ederek ele almaktadır. Bu boyutlar: fonksiyonel kısıtlılık, ağrı, psikolojik rahatsızlık, psikolojik yetersizlik, fiziksel engellilik, sosyal engellilik, özür (14,62). OHIP'in her bir boyutu için ayrı alt ölçekler hesaplanabilirken genel sosyal etki seviyeleri 49 sorunun hepsi kullanılarak hesaplanmıştır (62). Cevaplar Likert ölçeğine göre skorlanmaktadır. Anketteki sorular 0-4 arası puanlanan beş cevap seçeneğinden $(0=$ hiçbir zaman, $1=$ nadiren, $2=$ bazen, $3=$ sıklıkla, $4=$ çok sık) biri seçilerek yanttlanmaktadır. Her maddenin etkinliği Thurstone'un eşli karşılaştırma metodu kullanılarak belirlenmektedir. Sonuçlar her bir yedi alt grup için ayrı ayrı hesaplandıktan sonra hepsi toplanarak asıl sonuç hesaplanmaktadır. Alınan skorların yüksek olması hayat kalitesinin olumsuz etkilendiğini göstermektedir $(14,60,62)$.

OHIP'in en büyük avantajı; sorunların temsili hasta gruplarıyla yapılan konuşmalar sonucu oluşturulmuş olmasıdır. Yani ağız içi problemlerin meydana getirebileceği fonksiyonel, psikolojik ve sosyal etkiler hastalar tarafından belirlenmiștir (14,62). Nuttall ve ark.'na göre hastalar tarafından önemli olarak algılanan bu sosyal etkileri ortaya çıkararak ölçülebilme olasılığını arttırmakta ve dolayısıyla bu ölçeğin sofistike bir ölçek olduğu düşüncesini vurgulamaktadır (61).

Ölçekteki hiyerarşi, insanların hayatları üzerinde gittikçe yıkıcı bir etkiye sahip olan sonuçları ele almaktadır. Örneğin; ağız hastalıkları diş kaybı nedeniyle meydana gelmiş olabilir. $\mathrm{Bu}$ durum çiğneme yetersizliğine (fonksiyonel kısıtlılık) veya protez kullanımına bağlı ağrılara (rahatsızlık) neden olabilmektedir. Ayrıca bu durum istenilen veya ihtiyaç duyulan yiyeceklerin yenmesinde kısitlamalara neden olabilmektedir. Bu rahatsızlıklar kalabalık ortamda yemek yemeye engel olabilmektedir ve dolayısıyla kişinin ailesinden ve sosyal çevresinden uzak kalmasına (sakatlık) neden olabilmektedir. OHIP'in kullanıldığ çalışmalar; eksik dişlerin, tedavi edilmemiş bozuklukların, periodontal ataşman kaybının ve diş bakımı önündeki engellerin sağlık/iyi olma hali üzerinde artan etkileri olduğunu bulmuştur $(21,61,62)$.

49 sorudan oluşan OHIP, ağız sağlığıyla ilişkili objektif bir çizgi isteyen araştırmacılar ya da hekimler için uygundur. Ancak bazı araştırmacılar 49 sorunun tümünü kullanmayı gerekli görmemişlerdir. Çünkü istatistiksel olarak soru sayısı azaldıkça indeksin güvenilirliğinin de azaldığı bilinmesine rağmen anketin kolay ve basit olması da istenmektedir. Locker ve Allen ölçeklerin 
kısaltılma sebeplerini i) Ölçeklerin cevaplandırılması ve skorlanması uzun zaman alabilmesi ve klinikte bu kadar uzun zaman ayırmanın mümkün olmayabilmesi ii) Uzun anketlerin maliyeti arttırması iii) Hassas ve yaşlı hasta popülasyonu gibi toplumun bazı kesimleri için anketin uzun formunu cevaplamanın zor olabilmesi iv) Anketin uzun olmasi cevaplanmayan soru sayısının artmasina, bu nedenle de daha fazla veri kaybına ve çalışma grubundaki birey sayısının azalmasına neden olabilmesi şekilde açılamışlardır (63). Kısa bilgi formlarını tanımlamak için iç güvenilirlik analizi, regresyon analizi ve faktör analizi de dahil olmak üzere çeşitli istatistiksel teknikler kullanılmıştır. OHIP' in kısa versiyonu her boyut için iki soru içerecek şekilde 14 sorudan oluşmaktadır. OHIP-14'ün geçerliliği ve güvenilirliği Slade tarafından onaylanmıştır $(61,62)$.

Sonuç olarak: Ağız-diş sağlığg sorunlarının ve tedavi sonuçlarının değerlendirilmesinde, ataşman kazancı veya enflamasyonun gerilemesi, çürük dişlerin dolgularının yapılması gibi bir takım objektif klinik gözlemlere ek olarak, tamamen sübjektif karakterli hasta algısının da göz önünde bulundurulması gerekmektedir. Hastaların yaptığı bu sübjektif ölçümler hastaların bakış açısıyla tedavinin ve hastalığın değerlendirilmesini yaparak konvansiyonel klinik ölçümleri tamamlayıcı rol oynamaktadır. Hasta odaklı değerlendirmelerin, ağız ve diş hastalıklarının yarattığı objektif değişikliklere göre bireylerin günlük yaşantısı üzerinde daha anlamlı etkisi olduğu yapılan çalışmalarda bildirilmiştir. Ayrıca hekimin hasta üzerindeki bu etkenler hakkında bilgi sahibi olması, hastanın beklentilerini daha iyi anlaması ve gerekli tedavilerin uygun şekilde planlanması açısından önemlidir.

\section{KAYNAKLAR}

1. Farquhar M. Quality of life in older people. In: Fitzpatrick $\mathrm{R}$, editor. Advances in Medical Sociology. Greenwich, Connecticut: JAI Press Inc. 1994.

2. Testa MA, Simonson DC. Assessment of quality-of-life outcomes. New England journal of medicine 1996; 334.13: 835-840.

3. Engel GL. The Need for a New Medical Modal: Challenge for Biomedicine. Fam Syst Med. 1992; 10(3): 317-331.

4. Muldoon MF, Barger SD, Flory JD, Manuck SB. What are quality of life measurements measuring? BMJ 1998; 316: 542-545.

5. Morton RP. Evalution of quality of life assessment $n$ head and neck cancer. J Laryngol Otol 1995; 109: 1029-1035.
6. Hecker DM, Wiens JP, Cowper TR, Eckert SE, Gitto CA, Jacob RF, Mahanna GK, Turner GE, Potts A, Logan H, Wiens RL. Can we assess quality of life in patients with head and neck cancer? A preliminary report from the American Academy of Maxillofacial Prosthetics. J Prosthet Dent 2002; 88.3: 344-351.

7. Wood-Dauphine S. Assessing quality of life in clinical research: from where have we come and where are we going? J Clin Epidemiol 1999; 52(4): 355-363.

8. Cunningham S, Nigel P. Quality of life and its importance in orthodontics. 2001.

9. The Whoqol Group. The world health organization quality of life assessment (Whoqol): Development and general psychometric properties. Soc Sci Med 1998; 46(12): 15691585.

10. Görgün Baran A. [Socialization and quality of life in old age]. Yaşlı Sorunları Araştırma Dergisi 2008; 1.2: 86-97.

11. The Whoqol Group. The World Health Organization quality of life assessment (WHOQOL): position paper from the World Health Organization. Soc Sci Med 1995; 41.10: 1403-1409.

12. Petersen PE. The world oral health report 2003: continuous improvement of oral health in the $21^{\text {st }}$ century- the approach of the WHO global health programme. Community Dent Oral Epidemiol 2003; 31(1): 3-24.

13. Evans DR, Burns JE, Robinson WE, Garret OJ. The quality of life questionnaire: a multidimensional measure. Am J Community Psychol 1985; 13.3: 305-322.

14. Allen PF. Assessment of oral health related quality of life. Health Qual Life Outcomes 2003;1.1: 40.

15. Fitzpatrick R, Fletcher A, Gore S, Jones D, Spiegelhalter D, Cox D. Quality of life measures in health care. I: Applications and issues in assessment. Bmj 305.6861 1992: 1074-1077.

16. Allison PJ, Locker D, Feine JS. Quality of life: a dynamic construct. Soc Sci Med 1997; 45.2: 221-230.

17. Locker D. Measuring Oral Health: a conceptual framework. Community Dent Health. 1977; 5: 3-18.

18. Spilker B. Introduction (Chapter 1). In: Spilker B. Quality of Life and Pharmacoeconomics in Clinical Trials, Lippincott-Raven, Philadelphia. 1996.

19. John MT, Hujoel P, Miglioretti DL, LeResche L, Koepsell TD, Micheelis W. Dimensions of oral-health-related quality of life. J Dent Res 2004; 83.12: 956-960.

20. Cunningham SJ, Hunt NP. Quality of life and its importance in orthodontics. 2001.

21. Brennan DS, Spencer AJ. Dimensions of oral health related quality of life measured by EQ-5D+ and OHIP-14. Health Qual Life Outcomes 2004; 2.1: 35. 
22. Naito M, Yuasa H, Nomura Y, Nakayama T, Hamajima N, Hanada N. Oral health status and health-related quality of life: a systematic review. J Oral Sci 2006; 48.1: 1-7.

23. Gerritsen AE, Allen PF, Witter DJ, Bronkhorst EM, Creugers NHJ. Tooth loss and oral health-related quality of life: a systematic review and meta-analysis. Health Qual Life Outcomes 2010; 8: 126.

24. Hatch JP, Rugh JD, Clark GM, Keeling SD, Tiner BD, Bays RA. Health-related quality of life following orthognatic surgery. Int J Adult Orthod Orthognath Surg 1998; 13(1): 67-77.

25. Cohen LK, Jago JD. Toward formulation of socio-dental indicators. Int J Health Services 1985; 19:27-30.

26. Reisine ST. Dental disease and work loss. J Dent Res 1984; 63.9: 1158-1161.

27. Gift HC, Atchison KA. Oral Health, Health and Health Related Quality of Life. Med Care 1995; 33(11): 57-77.

28. Gift HC, Redford M. oral health and the quality of life. Clin Geriatr Med 1992; 8(3): 673-683.

29. Locker D. Measuring Oral Health: a conceptual framework. Community Dent Health. 1988; 5: 3-18.

30. Locker D, Allen F. What do measures of 'oral health-related quality of life'measure? Community Dent Oral Epidemiol 2007; 35.6: 401-411.

31. Sischo L, Broder HL. Oral Health-related Quality of Life: What, Why, How and Future Implications. J Dent Res 2011; 90(11):1264-1270.

32. Durham J, Fraser HM, McCracen GI, Stone KM, John MT, Preshaw PM. Impact of periodontitis on oral health-related quality of life. J Dent 2013; 41.4: 370-376.

33. Locker D. Issues in measuring change in self-perceived oral health status. Community Dent Oral Epidemiol 1998; 26.1: 41-47.

34. Glick M, Meyer DM. Defining oral health: a prerequisite for any health policy. J Am Dent Assoc 2014; 145:519-520.

35. Cunha-Cruz J, Hujoel PP, Kressin NR. Oral health related quality of life of periodontal patients. J Periodont Res 2007; 42:169-176.

36. Ingle NA, Chaly PE, Zohara CK. Oral health related quality of life in adult population attending the outpatient department of a hospital in Chennai, India. J Int Oral Health 2010; 2.4: 45-56.

37. Öhrn K, Jönsson B. A comparison of two questionnaries measuring oral health related quality of life before and after dental hygiene treatment in patients with periodontal disease. Int J Dent Hygien 2012; 10: 9-14.

38. Akboyun N, Alkan N, Gürgan C. [Quality of Life and Periodontal Health]. Diş Hekimliği Dergisi. 5/2011; 22:101:56-61.
39. Gift HC, Reisine ST, Larach DC. The social impact of dental problems and visits. Am J Public Health 1992; 82.12: 1663-1668.

40. Reisine ST. Dental health and public policy: the social impact of dental disease. Am J Public Health 1985; 75.1: 27-30.

41. Klein H, Palmer CE, Knutson JW. Studies on Dental Caries: I. Dental status and dental needs of elementary school children. Public Health Reports(1896-1970); 53(19):751765.

42. Ainamo J, Barmes D, Beagrie G, Cutress T, Martin J. ve Sacro-Infirri J. Development of the World Health Organisation (WHO) community periodontal index of treatment needs (CPITN). Int Dent J 1982; 32:281-291.

43. Güçiz-Doğan B. [Basic Oral Health Indicators]. Toplum Hekimliği Bülteni. 2007; 26:2:40-46.

44. Leao A, Sheiham A. Relation between clinical dental status and subjective impacts on daily living. J Dent Res 1995; 74(7): 1408-1413.

45. Steele JG, Sanders AE, Slade GD, Allen PF, Lahti S, Nuttall $\mathrm{N}$, Spencer AJ. How do age and tooth loss affect oral health impacts and quality of life? A study comparing two national samples. Community Dent Oral Epidemiol 2004; 32.2: 107-114.

46. Locker D. Issues in measuring change in self-perceived oral health status. Community Dent Oral Epidemiol 1998; 26.1: 41-47.

47. Tubert-Jeannin, S, Riordan PJ, Morel-Papernot A, Porcheray S, Saby-Collet S. Validation of an oral health quality of life index (GOHAI) in France. Community Dent Oral Epidemiol 2003; 31.4: 275-284.

48. Yıldız S, Işı k G. [Effects of prosthesis on oral health and quality of life in geriatric patients]. İstanbul Üniversitesi Diş Hekimliği Fakültesi Dergisi 2012; 46.1:11-16.

49. Jung SH, Ryu JI, Tsakos G, Sheiham A. A Korean version of the Oral Impacts on Daily Performances (OIDP) scale in elderly populations: validity, reliability and prevalence. Health Qual Life Outcomes 2008; 6.1: 17.

50. Adulyanon S, Sheiham A. Oral impacts on daily performances (Chapter 14). In: Slade GD.Measuring Oral Health and Quality of Life. Chapel Hill, North Caroline, USA 1997: 151-171.

51. Astrom AN, Okullo I. Validity and reliability of the oral impacts on daily performance (OIDP) frequency scale: a cross-sectional study of adolescents in Uganda. BMC Oral Health 2003; 3(5).

52. Strauss RP. The Dental Impact Profile (Chapter 8). In: Slade GD. Measuring Oral Health and Quality of Life. Chapel Hill, North Caroline, USA 1997: 81-91. 
53. Strauss RP, Hunt RJ. Understanding the value of teeth to older adults: influences on the quality of life. J Am Dent Assoc 1993; 124.1: 105-110.

54. McGrath C, Bedi R. Population based norming of the UK oral health related quality of life measure OHQoL-UK@ . Br Dent J 2002; 193(9): 521-524.

55. McGrath C, Bedi R. Measuring the Impact of Oral Health on Quality of Life in Britain Using OHQoL-UK@. J Public Health Dent 2003; 63.2: 73-77.

56. McGrath, C, Bedi R. A national study of the importance of oral health to life quality to inform scales of oral health related quality of life. Qual Life Res 2004; 13.4: 813-818.

57. McCormack HM, Horne DJL, Sheather S. Clinical applications of visual analogue scales: a critical review. Psychol Med 1988; 18.04: 1007-1019.

58. Scott, J, Huskisson EC. Vertical or horizontal visual analogue scales. Ann Rheum Dis 1979; 38.6: 560.
59. Mumcu G, Inanç N, Ergun T, İkiz K, Gunes M, İslek U, Yavuz S, Sur H, Atalay T, Direskeneli H. Oral health related quality of life is affected by disease activity in Behçet's disease. Oral Dis 2006; 12.2: 145-151.

60. Başol ME, Karaağaçlığlu L, Yılmaz B. [Development of Turkish Oral Health Impact Scale-OHIP-14-TR]. Turkiye Klinikleri Dishekimligi Bilimleri Dergisi 2014; 20.2.

61. Nuttall NM, Steele JG, Pine CM, White D, Pitts NB. Adult dental health survey: The impact of oral health on people in the UK in 1998. Br DenT J 2001; 190.3: 121-126.

62. Slade GD. Derivation and validation of a short-form oral health impact profile. Community Dent Oral Epidemiol 1997; 25.4: 284-290.

63. Saub R, Locker D, Allison P. Derivation and validation of the short version of the Malaysian Oral Health Impact Profile. Community Dent Oral Epidemiol 2005; 33.5: 378383. 